\section{Resposta ao artigo: Fatores associados à não utilização da teleconsultoria por médicos da Estratégia Saúde da Família}

Response to the article: Factors associated with the non-usage of teleconsultation by Family Health Strategy physicians

Haroldo Luiz de Oliveira Neto

(https://orcid.org/0000-0002-6337-8268) ${ }^{1}$

Nicolas Nimer Merlo

(https://orcid.org/0000-0001-9918-0870) ${ }^{1}$

Aline Baggio

(https://orcid.org/0000-0001-5903-0026) ${ }^{1}$

Chaiana Esmeraldino Mendes Marcon

(https://orcid.org/0000-0001-7031-437X) ${ }^{1}$

${ }^{1}$ Universidade do Sul de Santa Catarina (Unisul). Tubarão SC Brasil.

Devido à alta demanda de serviços relacionados ao bem-estar físico e mental e ao seu vasto território, no Brasil, tem-se a necessidade de novos meios de obtenção e acesso à saúde. Um deles, a telessaúde, vem evoluindo de forma crescente, porém ainda não satisfatória.

O presente estudo evidenciou que a frequência de não utilização do serviço de teleconsultoria pelos médicos da ESF, no norte de Minas Gerais, foi de $55,8 \%{ }^{1}$. Porém, com a execução correta da telesaúde, o Brasil pouparia uma grande parcela dos gastos públicos em saúde. Um exemplo disso é o serviço de telesaúde de Mato Grosso ter economizado o equivalente a 700 mil reais no ano de 2018, apenas no serviço de eletrocardiograma ${ }^{2}$. Em comparativo com a Inglaterra, que é um país desenvolvido, o Serviço Nacional da Saúde estima uma economia de $\mathrm{R} \$ 35$ bilhões ${ }^{3}$.

Ademais, segundo a Organização Mundial de Saúde, a teleconsultoria pode ser extremamente benéfica para o melhor prognóstico de doenças crônicas, além de reduzir demandas excessivas dos serviços de atenção primária ${ }^{4}$, uma vez que, de acordo com o Conselho Federal de Medicina, existem mais de 900 mil pessoas na fila de espera para realizar alguma cirurgia eletiva ${ }^{5}$.

O estudo ainda ressalta a utilização de aplicativos nos celulares que facilitam a realização da teleconsultoria ${ }^{1}$. Além de ser uma forma de intermediação e comunicação entre os profissionais de saúde que aumentam a resolutividade dos problemas do paciente. Segundo o governo do estado de Pernambuco, que utiliza essa ferramenta, implantada em 2015, de junho de 2017 a junho de 2018, em mais de 57\% dos casos, essas teleconsultas tiraram o paciente da fila de espera. Em um ano, foram contabilizados mais de 1,1 mil atendimentos resolvidos, sem necessidade de agendamento com especialistas ${ }^{6}$.

Por fim, no Brasil ainda há uma adversidade muito difícil de ser combatida devido à sua imensa área territorial com múltiplas regiões interioranas e a má distribuição da APS nas áreas mais remotas. Além disso, a grande rotação de profissionais médicos nos postos faz com que se tenha um treinamento, muitas vezes, inadequado. Todavia, necessita-se maiores investimentos na infraestrutura de informática nos serviços.

\section{Referências}

1. Damasceno RF, Caldeira AP. Fatores associados à não utilização da teleconsultoria por médicos da Estratégia Saúde da Família. Cien Saude Colet 2019; 24(8):3089-3098.

2. Mato Grosso. Secretaria de Estado de Saúde. Notícias. [acessado 2019 Ago 21]. Disponível em: http://www. saude.mt.gov.br/noticias

3. Underwood G. Telehealth could save NHS England $£ 7.5 \mathrm{bn}$ - Pharmaphorum. [acessado 2019 Ago 21]. Disponível em: https://pharmaphorum.com/news/telehealthcould-save-nhs-england-7-5bn/

4. World Health Organization (WHO). Health and sustainable development. [acessado 2019 Ago 21]. Disponível em: https://www.who.int/sustainable-development/ health-sector/strategies/en/

5. Portal Médico. [acessado 2019 Ago 21]. Disponível em: https://portal.cfm.org.br/

6. Recife. Prefeitura da Cidade. Serviço de Teleconsultoria de Saúde do Recife tira usuários de filas de espera. [acessado 2019 Ago 21]. Disponível em: http://www2.recife.pe.gov. $\mathrm{br} /$ noticias/08/06/2018/servico-de-teleconsultoria-desaude-do-recife-tira-usuarios-de-filas-de-espera 
